Univerza v Ljubljani

Filozofska fakulteta

maiken.kores@gmail.com

\title{
STILISTIKA V CANKARJEVIH POLITIČNIH SPISIH: KRITIČEN PRISTOP
}

\begin{abstract}
V pričujočem članku raziskujem slog pisatelja Ivana Cankarja, natančneje sintakso znotraj njegovih političnih spisov in družbenokritičnih besedil. Pri analizi segmentov iz besedil uporabljam raziskovalno metodo kritične stilistike, ki povezuje stilistiko in kritično proučevanje ideologij v jeziku. Zaradi Cankarjevega značilnega sloga in družbeno-zgodovinskih okoliščin časa, $\mathrm{v}$ katerem je živel, nudi ta primer možnost bogate in poglobljene jezikoslovne analize $\mathrm{v}$ to, kakšno vlogo imajo same stilistične odločitve naslavljanju družbene kritike.

Ključne besede: kritična stilistika, Ivan Cankar, družbenokritična besedila, ideologija, stilistika
\end{abstract}

\section{Uvod}

$\mathrm{V}$ tem članku bom z uporabo metode kritične stilistike poskušala osvetliti, če in kako sintaksa oziroma slog v družbenokritičnih in političnih zapisih pisatelja Ivana Cankarja izražajo njegovo ideologijo in pogled na svet. Pri svoji analizi se bom opirala predvsem na delo Critical Stylistics (Jeffries 2010), ki bo ponudilo konceptualni in metodološki okvir, ker pa je omenjeno delo zasnovano po meri angleškega jezika, se bom oprla še na delo Brede Pogorelec (2011), ki obenem vsebuje temeljito analizo Cankarjevega proznega sloga. Primere za analizo bom črpala iz izbora Kako sem postal socialist in drugi spisi (2018), ki ga je uredil Primož Vitez. Prav zaradi obsežnosti Cankarjevega opusa namen te študije nikakor ni generaliziranje ali pripisovanje določenih stališč avtorju. Poglavitni cilj je že obstoječim stilističnim analizam pisanja (umetnostnih) besedil dodati pogled iz perspektive ideološkosti, torej prikaz, kako se v določenih primerih lahko skozi stilistične in sintaktične odločitve izraža piščeva ideologija, ter podati konceptualni in metodološki zastavek za nadaljnje raziskovanje ne le Cankarjevih del, 
ampak umetnostnih in neumetnostnih besedil, pisanih v slovenskem jeziku, s pomočjo kritične stilistike.

\section{Kritična stilistika}

Kritična stilistika je raziskovalna drža, ki jo karakterizira kritičen pristop do obravnavane snovi in ki se je razvila na osnovi kritične teorije diskurza. Medtem ko se drugi kritični pristopi, med katere sodi tudi $\mathrm{KAD}$, osredotočajo predvsem na družbenopolitične okoliščine, v katerih besedila nastanejo, kritična stilistika s proučevanjem slogovnih značilnosti besedila raziskavi doda jezikoslovno plat. Ena od njenih temeljnih predpostavk je, da so ideologije sestavni del družbe in zelo pomemben vidik sveta, v katerem živimo, in da je jezik neločljivo vpet v vse plati našega družbenega delovanja; ideologije so torej neločljiv del jezika. Ker, izhajajoč iz temeljnih predpostavk KAD, ne moremo govoriti o pravi nevtralnosti in so torej vsa besedila na nek način ideološka, z ideologijo ne mislimo namreč vedno le političnih ciljev, potemtakem igra stilistika tudi določeno vlogo pri prenosu ideologije, ki je lahko izražena eksplicitno ali implicitno. Kritična stilistika se konkretno osredotoča predvsem na dve plati, in sicer na samo ideološko konstrukcijo besedila in na vlogo bralca pri izpeljevanju ideološkega pomena. (Jeffries 2010, 1-11)

\section{Metodologija}

Za prikaz pisateljevih morebitnih ideoloških odločitev v njegovih političnih in družbenokritičnih spisih bom uporabila razvrstitev na izhodišča za opazovanje jezika, ki jih poda Jeffries $(2010,15)$. V nadaljevanju bom podrobneje opisala vsakega od izhodišč in njihov ideološki učinek ter jih ponazorila s primerom iz besedila. Zaradi posebnosti Cankarjevega sloga in ker je umetnostno besedilo nujno opazovati, upoštevajoč kulturnozgodovinski in družbeni okvir ter njemu pripadajoče slogovne lastnosti in posebnosti, se bom pri analizi izbranih odlomkov opirala na obstoječo in podrobno jezikovnostilistično raziskavo Cankarjevega sloga Brede Pogorelec (2011).

\section{Poimenovanje in opisovanje}

Poimenovanje je izbira določenega pojma oziroma leksema za označevanje referenta. Ker ima tvorec besedila po navadi več možnosti, 
kako poimenovati določeno predmetnost, gre za stvar osebne odločitve. Poimenovanje je lahko popolnoma nevtralno kot v primeru npr. osebnega lastnega imena ali pa bodisi pozitivno bodisi negativno konotirano, torej ideološko, in kot tako izraža tvorčevo mnenje oziroma njegov odnos do referenta (Jeffries 2010, 18); kot v naslednjem primeru to avtor doseže z izbiro pridevnika: "Slišal sem ob tistem času govor debelega gospoda" (Cankar, „Lepa naša domovina“, 59). Nenavadne tvorbe na morfološki ali leksikalni ravni imajo lahko v določenih kontekstih prikrit ideološki naboj (Jeffries 2010, 18), na primer: “... in narod je bil pahnjen nazaj $v$ najčrnejšo temo" (Cankar, Trubar in Trubarjeve slavnosti, 71). Cankar izraža posmehljiv odnos zlasti s prestavljanjem pridevnikov in ponavljanjem (Pogorelec 2011, 164), kar naredi tudi v naslednjem primeru, ko s pristavčno zvezo na dva načina poimenuje avstrijske diplomante, medtem ko v drugem delu stavka preko pridevnika izrazi svoje mnenje o ljudstvu: „,To je jugoslovansko jezikovno vprašanje, ki ga niso bili postavili avstrijski diplomantje, mojstri v neumnosti, temveč navdušeni ljudje, ki nobenega jezika ne znajo " (Kako sem postal socialist).

Razmerja med elementi v stavku so izražena v propoziciji, v kateri igra glagol ključno vlogo; hierarhično namreč razvrsti udeležence oziroma določi razmerja med njimi. Pretvorba glagolske zveze v samostalniško spremeni propozicijo, in kar je bilo najprej predstavljeno kot proces, predstavi kot trditev ali entiteto, s čimer predpostavi resničnost tega dejanja (Jeffries 2010, 21).

\section{Opisovanje dejanj/dogodkov/stanj}

Jeffries $(2010,50)$ za preučevanje ideološkega učinka glagola uporabi model prehodnosti, katerega povzame po Simpsonu $(1993,88)$, in sicer je to model, ki združuje pojem ideologije, enega osrednjih predmetov proučevanja KAD, in stališče pisca, ki je načeloma raziskovalna domena literature in jezikoslovja. Prehodnost naj bi pokazala, kako govorci s pomočjo jezika enkodirajo svojo predstavo o resničnosti in kako si razlagajo doživljanje sveta okoli sebe.

Pri tvorbi besedila, ki bi naj najustrezneje izpolnjevalo namero pisca, igra pomembno vlogo izbira polnopomenskega glagola (Jeffries 2010, 37); v slovenščini te delimo na podlagi tega ali se dejanje "pripisuje določeni osebi ali ne (osebne - neosebne), ali pripisuje dejanje osebku ali ne (tvorne - trpne oblike)" (Toporišič 2004, 345). Čeprav so te odločitve jasno ideološke zaradi izbire možnosti, ki nam najbolj ustreza, pa ni prav zelo jasno, v kolikšni meri so te odločitve zavestne 
ali namerne (Jeffries 2010, 50). Naslednji je dober primer zavestne izbire glagolov, katerih učinek je enačenje referentov, torej baronov, z živino: "Od berlinskega kongresa sem, torej dalje nego trideset let, je Evropa redila in pasla na stroške svojih narodov cel trop postopajočih grofov in baronov, da so premišljevali o položaju na balkanskem polotoku" (Cankar, Slovenci in Jugoslovani, 19).

\section{Enačenje in kontrastiranje}

Odnosi med besedami, ki jih jezikoslovje pojmuje kot nasprotne, izhajajo iz tradicije opisovanja jezika po načelih strukturalistične lingvistike, ki temelji na ločnici med langue in parole. „To pomeni, da naj bi leksemi ,imeli““ pomene, med katere sodi tudi nasprotnost, zaradi česar se zanemari, kako besedilo lahko prispeva k ustvarjanju pomena“" (Jeffries 2010, 63).

$\mathrm{Z}$ besedilom tvorec predstavlja neko verzijo resničnosti, kar lahko tako na medpovedni kot na nadpovedni ravni počne tudi " $z$ ustvarjanjem novih sopomenskih in protipomenskih parov; ti so lahko včasih sestavljeni iz besed, ki jih sicer ne bi nikoli povezali" (Jeffries 2010, 52). Protipomenski pari, še posebej relevantni za ideološko analizo besedila, so pari protipomenk, ki druga drugo izključujejo (če nisi A, moraš biti $B)$; pari protipomenk, ki dopuščajo pridevniško stopnjevanje na obeh ekstremih in vmes (vroče, zelo vroče, zelo mrzlo); pari protipomenk, $\mathrm{v}$ katerih sta obe sestavini odvisni druga od druge (če nekdo kupuje, drugi prodaja); pari protipomenk, ki opisujejo nasprotna dejanja (graditi, rušiti) (Jeffries 2010, 57-58).

Pri razpoloženjskih vtisih Cankar z izrazi lastnosti, kot so pridevniki, prislovi in glagoli, stopnjuje žalostno vzdušje, katerega kontrastno dopolnjujejo izrazi radosti, veselja in svetlobe (Pogorelec 2011, 110). Intenzivnost sporočila še poveča z vpeljavo "podobe oziroma metafore v najširšem pomenu besede" (Pogorelec 2011, 113).

Na skladenjski ravni z vzporednimi slovničnimi strukturami lahko enačimo dve ideji, "tako da ju postavimo na enako mesto znotraj dveh vzporednih stavčnih struktur, ki sta si sicer tako na leksikalni kot na semantični ravni identični" (Jeffries 2010, 53-54), s čimer se med njima ustvari začasen leksikalni odnos, kot to vidimo v naslednjem primeru, ki vzpostavi sopomensko razmerje med svobodo in lastnim domom: „,Dokazal je vsemu svetu, da je zrel za svobodo, zrel za lasten svoj dom " (Cankar, Očiščenje in pomlajenje, 40). 


\section{Ponazarjanje in naštevanje}

Med ponazarjanjem in naštevanjem ni bistvene jezikovne razlike; bralec mora pragmatično sklepati, za katero gre, čeprav razlikovanje med njima ni nujno bistvenega pomena (Jeffries 2010, 66). Lahko se izražata v obliki trodelnega seznama, ki v nekaterih kulturah vzbuja občutek celovitosti in zaključenosti - je torej simbolično popoln, pogosto pa se ga uporablja za nadomeščanje dejanske vsebine, zlasti ko je cilj slikanje pozitivne podobe -, medtem ko so štiri- ali večdelni seznami dojeti dobesedno (Jeffries 2010, 70, 73); ponavljanjem enega pojma, izraženega na več različnih načinov; pristavka, ki naniza najmanj dve besedi, besedni zvezi in stavka, ki v stavku opravljata isto skladenjsko vlogo in imata po navadi podobno strukturo (Jeffries 2010, 71). Ena od lastnosti Cankarjevega sloga je vzpostavljanje povezav prek medsebojne odvisnosti vsebine treh zaporednih prostih stavkov ali prek asindetične povezanosti znotraj enega stavka, pri čemer so ti členjeni načeloma na dva in tri dele (Pogorelec 2011, 97). Te slogovne odločitve so vidne tako na povedni kot nadpovedni ravni; pogosti so odstavki, razdeljeni na tri ali večkrat po tri stavčne enote, ločene s podpičji, ki se med seboj pomensko in oblikovno dopolnjujejo (Pogorelec 2011, 98). V naslednjem primeru lahko vidimo obenem trodelno členitev na ravni povedi in odstavka, in kako z njeno pomočjo avtor doseže učinek stopnjevanja ter tvori asociacije prek skladenjsko podobnih stavčnih struktur.

V teh časih nasilja, ponižanja in krivice, $v$ teh časih krvi, solzá in gladu se je narod in v njem vsak posameznik bridko zavedel svojega suženjstva, zavedel se je narod sramote svojega ponižanja, zavedel se je posameznik svojega golega beraštva, svoje odvisnosti od tujca. In vsakemu med vsemi je srce zakoprnelo po rešitvi iz te mlake in gnilobe, roke so hrepeneče segale po nečem višjem, po svetlobi, dobroti, lepoti (Cankar, Slovenska kultura, vojna in delavstvo, 45).

\section{Namigovanje in sklepanje}

Za proučevanje ideološke funkcije namigovanja in sklepanja $\mathrm{v}$ besedilih se moramo obrniti na pragmatiko, katere predmet proučevanja je to, kar je v jeziku implicitnega. $Z$ uporabo namigov in sklepov se namreč utrjuje položaj nekaterih ideoloških pozicij kot zdravorazumskih. Predpostavljanje obstoja oziroma resničnosti ideologij ima veliko moč; če te ideologije namreč niso del propozicije izreka, niso podvr- 
žene tolikšnemu nadzoru ali prepraševanju njihove resničnosti (Jeffries 2010, 93). Kot vidimo v naslednjem primeru, odebeljeni del stavka ne spada v propozicijo stavka, temveč je v obliki samostalniške zveze, kar predpostavi njegovo resničnost: „,Pod avstrijskim valptom, v svoji ječi in revščini in mnogoštevilnih nadlogah smo povzdignili svojo kulturo tako visoko, da je kras in veselje " (Cankar, Slovenci in Jugoslovani, 26).

\section{Določanje prednosti}

Proučevanje površinske oblikovanosti besedila tako na povedni kot nadpovedni ravni razkrije odločitve pisca pri oblikovanju prvin stavka. Pogosto se na koncu pojavi beseda ali besedna zveza, ki da zaokroži misel in poudari njen pomen:

Zdaj med vojno pa se o kakem pametno urejenem šolstvu sploh ne da govoriti. In tako je bila naša bojazen čisto upravičena, da bodo otroci posuroveli na cesti in na gmajni, da se bodo ponevedoma navzeli duha krvi in nasilja, da otrok, ki v zatohli šolski klopi zaspi od oslabelosti in gladu, ne bo nikoli več sposoben za svetlo življenje; in da nam tako pojde v nič in v razsulo temelj naše narodne bodočnosti, mladina (Cankar, Slovenska kultura, vojna in delavstvo, 43).

Zakonitosti besednega reda določajo, da so izrazi razpoloženja $\mathrm{v}$ poudarnem zaključku; zato je pozornost nanje avtomatično naravnana (Pogorelec 2011, 98). Pripovedno distanco pa pisatelj vzpostavlja s subjektivnimi inverzijami besednega reda (Pogorelec 2011, 169).

\section{Zanikanje}

Zanikanje se lahko uporablja kot sredstvo ideološkega prepričevanja, ker bogati pripoved z izpostavljanjem odsotnih elementov. Pomembno je $\mathrm{z}$ vidika pragmatične moči, "ker bralca/poslušalca opozori na situacije, ki se ne odvijajo, a ki bi se pod drugačnimi pogoji morda lahko“ (Jeffries 2010, 106), kot v naslednjem primeru, kjer paralelizem še dodatno poudari učinek zanikanja: Hiti, umri za našo domovino! Zakaj njih je domovina in njih je oblast! Jaz sejem in žanjem, branim hišo in polje; ali ne setev ni moja in ne žetev, ne hiša, ne polje (Cankar, „Lepa naša domovina“, 60). Tovrstno igranje z domišljijo bralca lahko služi namenu prepričevanja. Zanikanje lahko poteka na morfološki, sladenjski in leksikalni ravni (Jeffries 2010, 110). 


\section{Poročanje o govoru in mislih soudeležencev}

Ponazarjanje besed in dejanj drugih vedno vključuje neko stopnjo manipulacije njihovih in bralčevih ideologij. O govoru naj bi sicer zvesto poročali, a vedno pride do odstopanja od tega, kar se je v resnici zgodilo, četudi to ni namerno (Jeffries 2010, 130). Premi govor z vidika bralca velja za najbolj verodostojnega, medtem ko gre pri polpremem govoru za poročanje $\mathrm{v}$ tretji osebi, kar omogoča piscu več možnosti za zlorabe in manipulacije, ki jih je težje odkriti (Jeffries 2010, 133). Opazna značilnost Cankarjevega pisanja je prisotnost pisateljevega komentarja in premikanje zgodbe iz prvega na drugi plan, s čimer postane zgodba prilika, da pisatelj izrazi svoje razmerje do krivic $\mathrm{v}$ svetu in dvoličnih, zlaganih medčloveških odnosih (Pogorelec 2011, 110).

„Za človeka z naturno kmečko pametjo, ki bi prav nič ne vedel, kaj je diplomacija, kaj politika in kaj državni pravdnik, bi ne bil jugoslovanski problem kar nič kompliciran in bi sploh noben problem ne bil. Tak človek bi rekel: , Če mislijo ti štirje narodi, da so si sorodni in da bi najlažje in najboljše živeli, če bi bili združeni, naj se zgodi po njih želji, naj si v božjem imenu zgrade zvezno republiko jugoslovansko! Koristen za vesoljno človeštvo je samo narod, ki je zadovoljen in ki ima pogoje in prostora, da uveljavi vso svojo moč.! " - Saj sem rekel: tako bi govoril človek, ki se svoj živ dan ni pečal z evropsko politiko, z avstrijsko še posebno ne" (Cankar, Slovenci in Jugoslovani 2018, 20-21).

Tu poročanje ni prav zares poročanje, temveč le sredstvo, da pisec izrazi svoje stališče. Pri Cankarju je ,sogovorec, poslušalec, bralec [...] navzoč le v domišljiji pisca in zato od pisca ustvarjen kot nekakšen notranji sogovornik, ob katerem pisec preskuša svoje inovacije“ (Pogorelec 2011, 165-166). Polpremi govor je pogost bodisi kot ugovor pisatelja ali samogovor lika (Pogorelec 2011, 110).

\section{Ponazarjanje časa, prostora in družbe}

Čas, prostor in družbo pisec ponazarja s pomočjo deiktikov, za katere je značilno, da nimajo vedno istega referenta; ta se namreč menja glede na govorčevo umestitev. Deiktika ima pomemben ideološki učinek, ker tvorec besedila doseže, da se bralec miselno postavi v deiktično polje, ki ga je zarisalo besedilo. Najbolj zanimiva za raziskavo so besedila, v katerih tvorec želi prepričati bralca, da opisuje resničnost. (Jeffries 2010, 156)

V Cankarjevem opusu opisi predmetnega igrajo vlogo avtorjeve 
eksplikacije sveta in družbe, v kateri živi (Pogorelec 1989, 105), in sicer je za krajinske opise značilna "zapovrstnost treh pomenskih jeder," ki so med seboj v pomenskem razmerju, opisi oseb pa so pogosto dopolnjeni s karikaturo (Pogorelec 2011, 108). Socialna deiktika vzpostavlja razmerja družbene bližine in razdalje ter hierarhične odnose med udeleženci z uporabo nagovorov, nazivov ali drugih fraz (Jeffries 2010, 149), kot za izraz ironije to stori Cankar: „Ko so topovi oznanili jugoslovansko Veliko noč, se je spomnila tudi naša ljuba oficijalna Avstrija na jugoslovanski problem in ga je začela po svoje reševati " (Cankar, Slovenci in Jugoslovani, 20).

\section{Sklep}

Slog je vsekakor sredstvo za izražanje piščeve ideologije, najsi je to namerno ali nenamerno. Četudi pisec uvodoma eksplicira, da je vsebina besedila le njegovo osebno stališče in ne politični tekst, njegova uporaba ironije, inverzije, besed $\mathrm{z}$ negativno konotacijo in druge subtilne spremembe na ravni besednega reda pri bralcih a priori ustvarijo stališče o obravnavani temi. Na bralca učinkuje tudi ponavljanje centralne misli skozi besedilo bodisi v obliki ponavljanja ene besede (,domovina“) ali vsakokratno izražanje te besede s sopomensko besedo ali besedno zvezo. Globoka metaforika Cankarjevega sloga, ki ponekod povzroča občutek abstraktnosti, pripomore k bolj subtilnemu izražanju družbene kritike, ki je vendarle vsekakor prisotna. Veljalo bi si zastaviti vprašanje, ali ni tako izražanje, ki se na začetku ne predstavlja kot prepričevalno besedilo, a vseeno tako deluje, morda bolj učinkovito za prenos ideologije.

\section{Bibliografija}

Ivan CANKAR, 2018: „"Lepa naša domovina“"“V Kako sem postal socialist in drugi spisi, uredil: Primož Vitez, Ljubljana: Mladinska knjiga, 57-61.

—. 2018. Kako sem postal socialist in drugi spisi. Uredil Primož Vitez. Ljubljana: Mladinska knjiga.

Ivan CANKAR, 2018: „Očiščenje in pomlajenje.“ V Kako sem postal socialist in drugi spisi, uredil: Primož Vitez, 30-41. Ljubljana: Mladinska knjiga.

Ivan CANKAR, 2018: „Slovenci in Jugoslovani.“ V Kako sem postal socialist in drugi spisi, uredil: Primož Vitez, 18-29. Ljubljana: Mladinska knjiga. 
Ivan CANKAR, 2018: „Slovenska kultura, vojna in delavstvo."V Kako sem postal socialist in drugi spisi, uredil: Primož Vitez, 42-48. Ljubljana: Mladinska knjiga.

Ivan CANKAR, 2018: „Trubar in Trubarjeve slavnosti.“ V Kako sem postal socialist in drugi spisi, uredil: Primož Vitez, 67-83. Ljubljana: Mladinska knjiga.

Lesley JEFFRIES, 2010: Critical Stylistics. Hampshire: Palgrave Macmillan.

Breda POGORELEC, 1989: „Besediloslovni vidiki Cankarjeve proze.“ Jezikoslovne in literarnovedne raziskave. Ljubljana. 165-178.

—. 2011. Stilistika slovenskega knjižnega jezika . Ljubljana: ZRC SAZU.

Paul SIMPSON, 1993: Language, Ideology and Point of View. London: Routledge.

Jože TOPORIŠIČ, 2004: Slovenska slovnica. Maribor: Založba obzorja Maribor.

\title{
Maiken Ana Kores
}

\section{STYLE IN IVAN CANKAR'S POLITICAL WRITINGS: A CRITICAL APPROACH}

\begin{abstract}
Summary
The following study focuses on Slovenian writer Ivan Cankar's stylistic choices, on both the lexical and syntactic level, in his writings of a political and socially-critical nature. Critical stylistics, a research method that combines stylistics with the critical study of ideology in language, are used to analyze chosen segments; these have been taken from a recently-published collection of Cankar's political writings, entitled How I Became a Socialist and other Essays. The specificity of the author's style, as well as the particular sociopolitical moment during which he lived allow for an interesting and in-depth linguistic analysis on how stylistic choices made consciously or unconsciously during the production of a text can impact how its message is transmitted, therefore revealing the producer's ideological position and, possibly, their social criticism.
\end{abstract}

Keywords: critical stylistics, Ivan Cankar, social criticism, ideology, stylistics 